\title{
Pensar la pedagogía de la direccionalidad a través de la imagen-tiempo: un proyecto filosófico, curatorial y pedagógico a partir de la colección Artium
}

\section{LAURA TRAFÍ-PRATS}

\section{Resumen}

El artículo analiza los fundamentos y el proceso de investigación de un proyecto curatorial y pedagógico centrado en reactivar la colección ARTIUM (Vitoria, España). En este proceso el arte y la pedagogía se proponen como escenas de direccionalidad, o espacios de producción de diferencia entre las posiciones que el texto cultural, museal, curricular ofrece y las respuestas que sus intérpretes, estudiantes, espectadores proponen. Se discuten diferentes momentos que encarnan este proceso de investigación entre los que se incluyen:

1) La reactualización de los lenguajes expresivos de las obrasARTIUM a partir de una teoría deleuziana de la imagen y una pedagogía centrada en la direccionalidad, 2) la producción de un espacio museal dilemático centrado en crear conocimiento desde la memoria, experiencia y subjetividad de los visitantes, 3) la activación del espacio a través de un Laboratorio de lógicas de visión, 4) la producción de narrativas visuales que experimentan con la noción de la imagen-tiempo por parte de las participantes en dicho Laboratorio.

Palabras claves:

Pedagogía de la direccionalidad, imagen-tiempo, museo de arte contemporaneo 


\title{
Considering a pedagogy of address through the time image: a philosophical, curational and pedagogic project centered on Artium's collection
}

\author{
LAURA TRAFÍ-PRATS
}

\begin{abstract}
The article analyzes the foundations and research process of a curatorial-pedagogic project centered on reactivating ARTIUM's Collection (Vitoria, Spain). In this process art and pedagogy are seen as scenes of address, or spaces of production of difference between the positions that the cultural, museum, curricular text offers, and the responses given by its interpreters, students, viewers. Different moments of this research process are discussed, including: 1) The reactivation of the expressive languages of ARTIUMartworks through a Deleuzian image theory and a pedagogy of address, 2) the production of a dilemmatic museum space centered on producing knowledge from visitors' memories, experiences and subjectivities, 3) the activation of this space through a Laboratory of Logics of Vision, 4) the production

of visual narratives experimenting with the concept of image-time by the participants in such Laboratory.
\end{abstract}

Keywords: Pedagogy of address, time image, contemporary art museum 
El proyecto sobre el que voy a reflexionar en este artículo empezó en el 2011, a partir de una invitación de Mar Villaespesa y BNV Producciones para participar en la co-curaduría de la exposición Estancias. Prácticas Restituyentes sobre la Colección, ARTIUM, el Museo-Centro Vasco de Arte Contemporáneo, situado en Vitoria-Gasteiz, Euskadi, que es una de las regiones motores del Estado español, situada en el noroeste del país.

La exposición Estancias se preguntaba sobre la posibilidad de crear experiencias de lo colectivo, de co-implicación desde el arte contemporáneo y sobre cómo repolitizar un arte reciente cuyas estrategias críticas y subversivas han sido neutralizadas por sus 10 años de institucionalización en el museo mencionado. Según Villaespesa y BNV (2011), Estancias conectaba con la tercera ola de crítica institucional, en el sentido de que

Aborda la necesidad de dejar de considerar como una excep-
ción la actividad artística y pensarla junto a otras formas de
acción en el ámbito de las relaciones sociales y de producci-
ón, lo cual ha abierto nuevas fases de "institucionalidad", po-
sibilitando nuevas relaciones entre instituciones y creación,
o la construcción de nuevas instituciones de lo común (p. 6).

Aquí la noción de "prácticas restituyentes" significa "tratar de devolver potencialidades a una serie de obras señaladas de la Colección ARTIUM, por medio de ciertos ejercicios curatoriales que parten de la premisa de la activación" (p.6-7). Así que el proyecto se compuso por un número de 4 estancias curadas por diferentes investigadores y colectivos creativos que incluyeron Valentín Roma, Fundación Rodríguez, Buleoga z/b y yo misma. Cada estancia empezaba con la selección de un número de obras de la colección ARTIUM, y un número de eventos que generarían procesos colectivos de activación. 
Por ejemplo, el ejercicio curatorial de Fundación Rodríguez se centraba en problematizar las visiones de la cultura en una ciudad media, donde mayoritariamente la cultura vasca se identifica con lo popular y el folclore. Fundación Rodríguez se preguntaba si después de 10 años de existencia, el museo ha llegado a construir una audiencia implicada, cuando la opinión mediática ha cuestionado permanentemente la gran inversión de fondos públicos dedicados a construir desde cero una colección de arte reciente y al mismo tiempo, que el museo nunca haya mostrado esta colección al completo al público de la ciudad. En definitiva, la Estancia 2 de Fundación RDGZ se centraba en varias acciones-reactivaciones que problematizaban tanto los mitos de la identidad vasca definida por la alta cultura del arte como los mitos de una cultura popular folclorizada, construyendo desde el humor, la ironía y la participación choques entre ambas, y así performando otras posibilidades de producción cultural en el espacio público.

Una de las acciones fue la construcción de unos cabezudos ARTIUM, con uno de los artistas más popularmente reconocidos de la ciudad un maestro de cabezudos. Estos cabezudos realizaron una marcha de cabezudos vitorianos en el museo, así como varias visitas guiadas, incluyendo una que permitía dormir en el museo. También llevaron a cabo una rueda de prensa en el techo del museo sobre sus acciones, explicaron otras historias de la colección ARTIUM y finalmente el día de la clausura de la exposición salieron a la calle y lanzaron las fotocopias de la colección al viento.

Yo fui invitada a curar la Estancia 4, con el objetivo de traer modelos experimentales de pedagogía de la espectatoriedad a un marco de educación de museos institucionalizada y dependiente de las mismas fórmulas de visitas guiadas, talleres para escuelas, charlas de artistas...

¿Como se puede pensar en la pedagogía como una forma de reactivación y reactualización de lo político a través del arte y en un contexto institucionalizado? ¿Se puede? Y aunque teóricamente no tenía ninguna duda de que se puede porque existe una larga bibliografía en museografía crítica y proyectos asociados que lo demuestra (e.g. HOOPER-GREENHILL, 2000, 2011; GAROIAN, 2001; FRENKEL, 2007; POLLOCK \& ZEMANS, 2007), prácticamente tenía mis dudas sobre si esto sería posible en el contexto institucional, ideológico y de trabajo que ARTIUM posibilitaba. Pensé que valía la pena comprobarlo.

Empecé a trabajar en el proyecto, con un claro interés por conectar con la idea propuesta por Villaespesa y BNV de uti- 
lizar la teoría crítica para socavar la naturaleza problemática del sujeto educativo en el contexto museal, como un sujeto limitado prácticamente a una visión como repetición o espejo del mismo museo, una visión que no es multidimensional ni corporeizada, ni centrada en una producción cultural independiente, ni en el conocimiento como diferencia diferenciadora. En este sentido, pensé que sería interesante reactivar diferentes obras de la colección ARTIUM abordando lo que en pedagogía se denominan los espacios paradójicos, dislocados, analíticos de la direccionalidad.

Elizabeth Ellsworth (2005) define el poder paradójico de la direccionalidad como algo invisible, no es una cosa sino una relación que configura los vínculos entre un texto cultural y sus intérpretes ya sean lectores, espectadores, estudiantes, posicionándolos en relaciones de poder, conocimiento, deseo, afecto. Ellsworth teoriza sobre las paradojas que este poder genera, entendiendo que existe un espacio de producción de diferencia entre las posiciones acceptabes/esperadas/deseadas/prescritas que el texto cultural ofrece y el desbordamiento de las mismas a través de las respuestas de los intérpretes.

Ellsworth añade que existen obras de arte y, especialmente obras cinematográficas, que funcionan como historias parciales, resistiendo una función mimética, construyendo diálogo analítico. Obras que actúan la direccionalidad no para repetir lo mismo, construir consenso o un buen encaje. No. Estas obras construyen direccionalidad como una lógica abierta de posibilidad, centrada en la obligación ética de confrontarnos con lo que nos es desconocido, en la que los estudiantes escuchan sin tener una razón o propósito final, en la que enseñar ocurre sin autoridad.

Pensando en la idea de direccionalidad me propuse dos objetivos:

1. Elegir obras de la colección ARTIUM cuya conceptualidad estética planteara que ver no es necesariamente un acto que se limita al mirar sino a una comprensión extendida en torno a los discursos y políticas que sostienen nuestro deseo de conocer. Obras que alterasen formas de mirar y modos de direccionalidad basados en un deseo de conocer basado en controlar/fijar la diferencia, la ambigüedad, el exceso, la memoria. Obras conectadas al carácter desfamiliarizado, inhóspito de las condiciones contemporáneas definidas por la globalización, la migración, la mobilidad. Imágenes que sugirieran un encuentro entre estética y ética en las cuales los hechos del mundo no se presentan como algo dado, sino como algo que implica una negociación, un encuentro entre el espectador y el otro. 
2. Me propuse reactualizar la pedagogía de la direccionalidad desde el concepto de imagen-tiempo, que Gilles Deleuze elabora y analiza en su obra Cinéma 2 (2010). La imagen-tiempo es una imagen que se despliega, "que nos ofrece una perspectiva temporal de la imagen que problematiza las categorizaciones sobre la 'verdad' y la 'realidad del mundo' de la filosofía clásica” (COLMAN, 2011, p. 180). Para Cowie (2011), la imagen-tiempo conlleva producir una imagen que en lugar de ser, deviene. Una imagen que suspende, amplifica el momento y sitúa al espectador en un estado de incerteza, en el que cuanto más miramos, y cuanto más tiene que añadir nuestra imaginación a la imagen, nos hacemos más conscientes de que estamos mirando. Para Deleuze esto se consigue explotando de manera experimental los elementos expresivos de la imagen y la manipulación del montaje (acción) y tiempo, creando una desterritorialización del lenguaje que hace aparecer de nuevo lo colectivo a partir de un lenguaje expresivo centrado en lo menor: "[Una imagen] que rechaza la violencia capitalista a partir de inventar nuevas formas de narración evitando la ficción y etología" (DELEUZE, 2010, p. 222).

La imagen-tiempo, por consiguiente, sugiere una forma de pensar en imágenes que tiene correspondencias con las paradojas de la direccionalidad en pedagogía, porque a diferencia del cine industrial de Hollywood o el cine utópico del Constructivismo Soviético, o el Cine propagandístico de la Alemania Nazi, el cine de la imagen-tiempo no propone soluciones finales a las cuestiones que se plantean. Por el contrario, la imagen-tiempo:

Afirma una incapacidad para figurar cuáles son las respuestas ciertas y adecuadas a un problema. Para la mayoría de filmes de la imagen-tiempo, el simple proceso de figurarse cuál es el problema es más que suficiente ... (RUSHTON, 2012, p.5)

En este sentido, la imagen-tiempo construye una direccionalidad sin autoridad, no trata de representar un conocimiento que la precede y está ya establecido en nuestras mentes, sino que es un pensamiento que viene desde fuera y que nos coge por sorpresa, nos embarga, nos afecta y nos hace repensar cómo funciona el mundo.Y es importante precisar que en la filosofía de Deleuze, una imagen no es una representación o copia de algo, sino nuestras prácticas de percibir y aprender objetos, relaciones, eventos en el espacio espectatorial.

Y en este sentido, al igual que la pedagogía de la direccionalidad, la imagen deleuziana no cumple una función mimé- 
tica. Las imágenes creadas para una pantalla intervienen en el mundo de la pantalla, pero también en el mundo de los cuerpos fuera de la pantalla, son capaces de producir nuevos conceptos, y transformar nuestras formas de percibir el mundo y por consiguiente, nuestras subjetividades (COLMAN, 2011).

Escogí tres obras de la colección y las empecé a pensar y cuestionar como espacios de direccionalidad y espacios de visión, como creadoras de conceptos y preguntas filosóficas. Como veremos éstas tres obras no son fílmicas, sino fotográficas. En la actualidad la teoría sobre la imagen-tiempo se discute en un campo expandido de prácticas críticas de producción y escritura de y sobre imágenes que no se reducen al cine y que tienen en común cuestionarse el sentido de la imagen como forma de comunicación en una cultura visual dominante donde con frecuencia las imágenes proliferan para suprimir, censurar, destruir conocimiento, percepciones, diferencias y arrebatarnos el mundo a partir de reducir la profundidad del evento a iconos abstractos, distanciados, repetitivos que no facilitan un reconocimiento empático de la realidad, sino vouyeristico y espectacularizado. En este arrebatamiento del mundo, la catástrofe histórica que aparece en las noticias de la CNN puede presentarse con los mismos códigos de movimiento, temporalidad y percepción que los utilizados para presentar la catástrofe virtual en el último film de acción o guerra de Hollywood (DIDI-HUBERMAN, 2007).

Estas son las 3 obras:

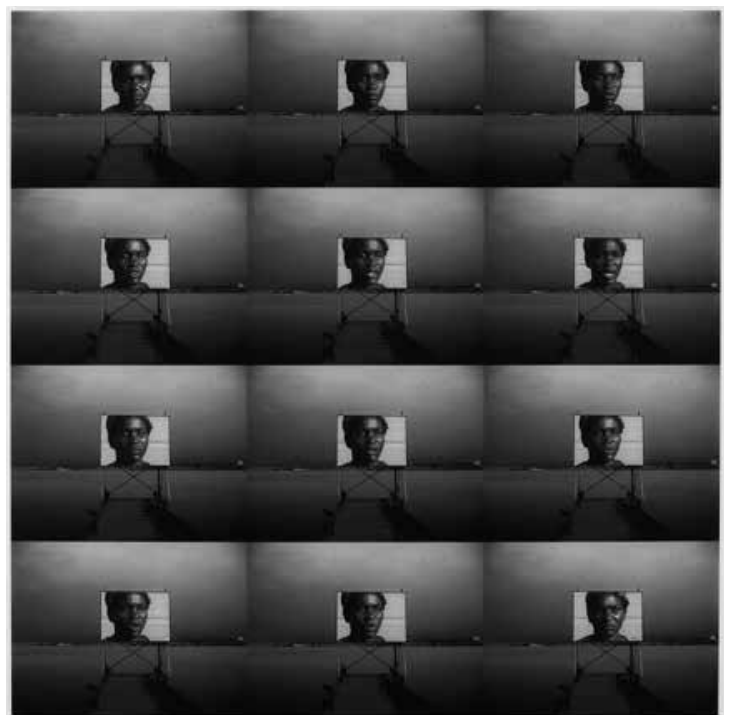

Figura 1

Alfredro Jaar, The Salt of the Sea, 2006, ARTIUM de Âlava, Vitoria-Gasteiz. Depósito Juan Bonet Gambinns, (C) Gert Voor in't Holt 
The Salt of the Sea de Alfredo Jaar presenta en orden reticular 12 momentos constituidos por un pasaje espectatorial abierto en una marina, que nos conduce al rostro de una mujer llorando proyectado en una pantalla. En términos de Deleuze, nos enfrentamos a un caso de una imagen con un marco extremadamente afectivo. Estamos confrontados con instantes de un rostro y un paisaje que se totalizan en el tiempo a través de su repetición en un mismo espacio. La imagen-afección funciona de forma diferente a la imagen-percepción que tiende a dominar más claramente el cine industrial. Mientras la imagen-percepción se centra en el flujo del movimiento como acción sensoriomotor, una acción lleva a otra en una línea lógica de eventos, la imagen-afección, sigue una visión dialógica de la direccionalidad, no es una imagen representacional, sino una imagen que crea condiciones de afecto, que no juzga, sino que proyecta intensidades causando una expresión dinámica en un cuerpo con la posibilidad de alterar su trayectoria. En el caso de The Salt of the Sea, al ser una imagen fotográfica con tiempo, pero sin movimiento, la posibilidad de la alteración alude principalmente al afuera de la imagen, los cuerpos en el espacio espectatorial.

Los 12 fotogramas que componen esta imagen, han sido extraídos de Muxima, el filme que Jaar produjo durante su viaje a Angola. Muestran una situación en el que una versión de este filme se proyecta en este espacio al aire libre. Jaar escoge para construir esta imagen el momento en el que se narra el testimonio de una mujer sobre la pérdida de su hija en el contexto de una Guerra Civil de más de 30 años de duración que ha devastado Angola. La fracturación y descentramiento del movimiento del vídeo original, movimiento definido por el fluir de los gestos y la narración del testimonio, queda transformado en instantes de tiempo, en los que el pathos del rostro y su expresión se sitúa en una tensión sin solución con el ethos del paisaje africano. En la investigación visual que Jaar conduce en Angola, persiguiendo la pregunta $i$ es posible imaginarse Angola desde una perspectiva blanca que a la vez sea crítica y desmontadora de los tropos colonialistas? (POLLOCK, 2007), esta va a ser una de las primeras imágenes que construye abandonando los rastros y capas de historia y colisiones de historias que ha investigado a través del filme. En esta imagen Jaar se deshace de narrativas basadas en reconstruir el pasado, para situarse en el presente e imaginar el futuro, creando un nuevo montaje que le permite reformular los signos del desastre y la desesperación de la guerra, la colonización cultural y económica en términos de posibilidad. 
En relación al cine de Michelangelo Antonioni, Deleuze habla de la necesidad de una objetivización de la subjetividad de los personajes y de lo significativo que puede ser un espacio marcado por el vacío, por la desaparición de lo humano para llevar a cabo dicha objetivación. Esto posibilita una forma de ver los personajes no desde su interior, sino afectados por cosas que llegan desde un afuera hecho de objetos, espacios, eventos que no controlan. En las historias de Antonioni, los personajes no son constructores o resolutores de su destino, algo típico de las películas comerciales, sino que los sucesos les acontecen, son cosas que pasan (RUSHTON, 2012). En el caso de The Salt of the Sea, el borrado del testimonio en favor de una expresión de llanto en el paisaje es para mi un claro ejemplo de este movimiento de objetivización de la subjetividad. Dicha objetivización, permite ver el pasado, la historia como cosas que ocurren, que definen o fijan nuestro presente y futuro. En los filmes de Antonioni, estos espacios de posibilidad positiva, se tienden a enunciar al final de sus filmes. A pesar de que en el filme ha dominado una narrativa en el que uno o varios de los personajes encuentran el mundo como algo intolerable (en nuestro caso la mujer que llora por la muerte de su hija), otros personajes (en nuestro caso Jaar y los espectadores situados al otro lado de la pasarela que lleva a esta pantalla) pueden ser capaces de reinventar el circuito de relaciones. En este caso pueden reinventar el montaje de imágenes para convertirlas en una zona abierta de experimentación que se resiste a una representación que repita, una representación que rompa imaginarios y relaciones que continúen matando, colonizando, anclando al otro en una historia permanente de desastre y dominación sin cuestionarnos nuestras implicaciones.

We Will All Die es una fotografía de gran formato del fotógrafo vasco Mikel Eskauriaza. Presenta un perfil geológico de muchas capas, algunas de ellas encontradas, algunas creadas. Deleuze utiliza el término de topología para hablar de los espacios complejos que construye el cine, que son en sí mismos la creación de un mundo original que puede respirar conciencia. Esta conciencia surge del examen del funcionamiento de cada elemento y su contribución a una situación espacial: Mirando de abajo hacia arriba vemos unos pocos centimetros de la horizontal de un asfalto gris, el corte de terreno, una valla que delimita un espacio natural privado, y unos cables que cuelgan casi paralelos a la carretera. En ellos el artista ha instalado un cartel con la frase "vamos a morir", que queda situado en 
el centro de la imagen. Detrás de todos estos enmarcamientos vemos unos metros cuadrados de monte, árboles, vegetación y claros sin más referencia. Deleuze describe el significado de la imagen-tiempo a través de su forma topológica. Es una imagen que no es espacio-movimiento, sino que sus características más importantes son tiempo y topología. La topología estudia la transformación de las cosas a través de diferentes clases de interconexiones y en este caso la topología de este lugar puede explicarse a partir de la imagen-cristal, como una imagen que accede a diferentes modalidades de tiempo, que no ocurren tanto a través del movimiento como de la memoria: pasado del monte vasco, cuando éste no era un lugar dominado de paso sino una ecología de vida. Presente marginal, exotizado, urbanizado, turístico. Y futuro, ¿quizás enunciado a través de la frase "vamos a morir"? Es decir, diferentes tiempos se encuentran en la imagen para construir una situación dilemática. La obra de Eskauriaza habla de las transformaciones del paisaje natural y urbano, en especial formas de paisaje que presuponen utopías sociales y naturales. Como ya hacían las estéticas shock de la Internacional Letrista, Eskauriaza inserta mensajes en sus imágenes con el fin de reorganizar visiones y relaciones con estos lugares que nos hagan sospechar que algo imprevisible está sucediendo.

Y en este sentido, la energía que crea una imagen-cristal puede derivar en la producción de índices que vienen a nuestro encuentro: La frase "Vamos a Morir" funciona como índice que señala objetivamente, sin juicios o pasiones, sin personalizaciones o cronologías que algo especifico va a ocurrir, una muerte colectiva. ¿Quién habla? ¿Qué espacio común incluye ese "vamos"? ¿Es un espacio común humano o habla desde una conciencia del afuera? Siguiendo las ideas de Felicity Colman (2011), lo que se construye aquí es una imagen a través de un cuerpo actuando como "espacio cerebral topológico" (p. 173), el cuerpo del espectador. La imagen-cristal produce topografías como ésta, que Deleuze llama espacios-cualquiera, en el que el espectador queda sujeto no tanto al tránsito, circulación, movimiento en el espacio como a lo político-afectivo. Es decir, sujeto a las relaciones éticas de un espacio vacío que en la tradición cinematográfica y filosófica Europea posterior a la Segunda Guerra Mundial, es presentado como hemos mencionado anteriormente con la referencia a Antonioni, como un espacio existencial que puede señalar al mismo tiempo el pasado de la destrucción como una situación potencial de 
futurabilidad. En este caso, de manera diferente a lo que hemos visto en The Salt of the Sea, esta posibilidad no se formula en términos positivos, sino en términos de posibilidad-intrigante o posibilidad-perturbadora.

Limpieza social es una fotografía que condensa uno de los momentos de la performance con el mismo nombre que la artista Regina José Galindo describe de la siguiente manera: "Recibo un baño a presión con una manguera, método utilizado para calmar manifestaciones o bien, para bañar a los recién ingresados a prisión" (www.reginajosegalindo.com, 2013). La imagen-tiempo trae un nuevo tipo de personaje a la pantalla. Uno que en lugar de actuar, ve, muestra, pero nunca resuelve. Como artista guatemanteca, Galindo vive y trabaja desde un país hecho de silencios, silenciamientos y olvido perpetrado en territorios y cuerpos subyugados y borrados, Galindo utiliza su cuerpo como herramienta de localización móvil y de dislocación de la historia, Deleuze la denominaría imagencomportamiento, para mostrar formas de violencia comunes y a través de su repetición en un nuevo contexto, producir una transformación de su sentido colectivo. Es en relación a esta transformación, que podemos conectar Limpieza Social con el argumento de que la imagen-tiempo es fundamentalmente creadora de una imagen política. Política en el sentido de que crea posibilidades para una organización diferente a partir de una interrupción del lugar común, del cliché, de lo aceptado o de lo acomodado. A partir de actuar y hacernos imaginar la indefensión, la desposesión, la precariedad, la vulnerabilidad, Limpieza social nos sitúa en una ética que nos hace escoger, posicionarnos en los límites de lo visible y lo pensable, forzando extrañamiento y desterritorializacion como recursos críticos. Crea el potencial para un espacio colectivo de reconocimiento de lo menor y lo subalterno. Y a diferencia de los cines moderno-utópicos o idealistas, el colectivo, la impliación, la responsabilidad colectiva todavía no está aquí, la audiencia es llamada a responder, pero no predeterminada con la representación de una reacción unitaria o unificadora.

Las tres obras escogidas de la colección funcionan como documentos parciales de realidad o documentos en evolución, que devienen, que abordan la comprensión del mundo desde encajes imperfectos, como afirmaciones del fracaso de la función mimética del discurso. Para Ellsworth (2005) "los textos parciales no tratan de producir un sentido racional o lograr comprensión o un encaje entre el texto, el mundo y las inter- 
pretaciones compartidas de los lectores" (p. 164). No tratan de producir una verdad o un cierre, sino un territorio de responsividad y responsabilidad textual-social-política, un territorio de obligación ética, una escena de direccionalidad en la que:

Se me saluda como interlocutora no sobre la base de que el diálogo comunicativo lleva a la comprensión, a salvar la brecha entre el yo y el otro o entre el yo y el yo, o a establecer un terreno común para emprender la acción "correcta". Mi obligación ética para responder al saludo no es la obligación de tratar de conocer al otro o encontrar un terreno común. [Es] una obligación para respetar a un otro absoluto y no conocido. Una escena de direccionalidad pedagógica en la que estoy obligada a escuchar sin saber por qué, sin comprender y antes de saber qué es lo que voy a oir (p. 164-165).

Las 3 obras no tratan de embellecer o borrar el conflicto, el sufrimiento o la otredad, sino construir en los términos de la imagen-tiempo, narrativas menores que restauran sentidos de lo colectivo. Y en este sentido, estas imágenes son imágenes-pensamiento que existen creando contrapuntos y disrupciones dentro de otras ecologías de imágenes contemporáneas comunes en los mass media. Ecologías de imágenes que borran el sufrimiento, y la humanización de historias situadas de vida y muerte en condiciones minoritarias de diferencia radical, resultando en la imposibilidad de empatizar y reconocernos en el otro, de transformar nuestra subjetividad a partir de enfrentarnos con una alteridad alteradora.

Una vez escogidas las obras, el siguiente paso era diseñar un espacio expositivo dentro del museo, y dentro del proyecto Estancias. Seguí los planteamientos de Vera Frenkel (2007), una artista, curadora y educadora canadiense que propone que los museos a través de sus dispositivos de exposición deben promover pedagogías que cultiven la incertidumbre y el conocimiento difícil y eviten el cierre, el olvido o la espectacularización:

El conocimiento dificil" no se puede empaquetar como una muestra de eventos históricos finitos como si en cualquier caso los eventos históricos se pudieran terminar. Requiere de prácticas artísticas y estructuras museales que permitan espacio y tiempo para que el conocimiento difícil permanezca dilemático, sin resolver, evocado en lugar de afirmado y presentado a la imaginación a través de una mezcla de ausencia, lo indi- 
recto y lo incompleto para sacar al espectador de su pasividad y hacer el mundo, el mundo del arte, de la teoría y de la implicación social el lugar natural de existencia de lo difícil (p. 121-122).

Así que mi exposición se centró en constuir un espacio direccional incierto, dilemático e interpelador. En este mismo sentido fui fiel al ideario establecido por Villaespesa y BNV (2011) en el que anunciaban que

Las obras señaladas se presentan en la Sala Este Baja de ARTIUM, desde donde operan y configuran cada una de las cuatro estancias, pero no en el sentido de mostrarse en un espacio compartimentado, sino en el etimológico de permanencia durante cierto tiempo en un lugar determinado. La Sala, además de lugar de exposición, es espacio de trabajo y máquina (p. 8).

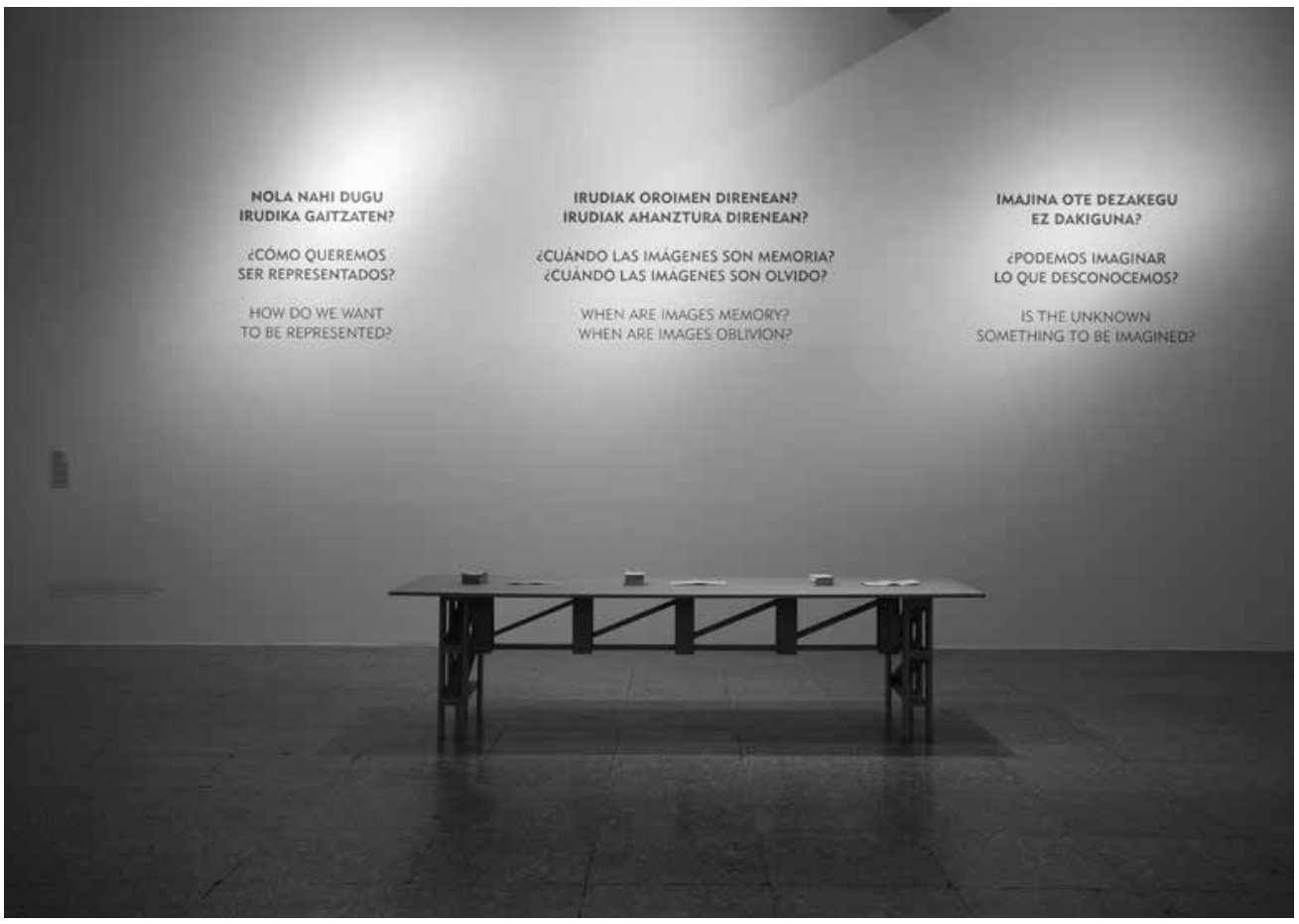

Figura 4 Estancia 4, ARTIUM de Álava, Vitoria-Gasteiz, (c) Gert Voor in't Holt
Y siguiendo estas ideas, decidí que la Estancia 4 presentaría inicialmente 3 preguntas y que las 3 obras señaladas sólo aparecerían más tarde en el contexto del Laboratorio de lógicas de visión, el momento de activación directa de la Estancia. Aunque es cierto que las preguntas conectaban con los procesos de in- 
vestigación implicados de la imagen-tiempo y sus formaciones en las obras descritos previamente, también eran lo suficientemente amplias y con el potencial para ser asociadas con la diversidad de experiencias biográficas y culturales que los visitantes traen consigo al museo:¿Cómo queremos ser representados? ¿Cuándo las imágenes son memoria? ¿Cuándo las imágenes son olvido? ¿Podemos imaginar lo que desconocemos?

Charles Garoian (2013) sugiere que existe una relación "associativa, aunque indeterminada entre nuestros recuerdos individuales, privados y la memoria pública del museo" (p. 84). En este sentido, la oclusión de las obras en favor de las preguntas pretendía construir un espacio en el que aprender no necesariamente empezara por los contenidos/narrativas del museo, sino por las historias, memorias y procesos simbólicos de los visitantes.

Junto a estas preguntas, diseñé un panfleto que se podía recoger en la exposición, que proponía a los visitantes a enviar al museo imágenes y textos que proporcionaran respuestas individuales a una o varias de las preguntas. Las postales también invitaban a los participantes a traer dichas imágenes y textos para participar en un Laboratorio de lógicas de visión que duraría 4 tardes. El propósito de dicho Laboratorio era construir asociaciones potenciales entre imágenes y textos aportados por los participantes, las preguntas, las 3 obras seleccionadas y la teoría crítica y pedagógica de la direccionalidad y la imagen-tiempo.

El Laboratorio de lógicas de visión se configuró por un grupo reducido, aunque diverso, de participantes todas mujeres de edades diferentes, que a lo largo de las sesiones se revelaron complejas y situadas en cadenas de posiciones que incluían las de artista, estudiante de arte, estudiante de educación, profesora universitaria del area de educación artística, educadora de museo, becaria, doctoranda, currante en diversidad de trabajos complementarios, escritora, lectora, montañista, sujeto cuya cotidianidad está distribuida por tránsitos constantes entre diferentes espacios de vida, trabajo, familia, placer, geografías, memorias, diferentes identificaciones con la/s cultura/s y tradiciones euskaldunas, diferentes lenguas vehiculares euskera, español, catalán, inglés.

Un documento relevante de presentación del grupo como subjetividad y diferencia son sus respuestas a la pregunta que inauguró las sesiones del laboratorio ¿Quién es espectador? ¿Qué hace un espectador en un lugar como éste?Y lo importante antes de leer las respuestas es saber que las sesiones de clase se 
realizaron en unas mesas móviles de trabajo que ARTIUM situó directamente en la sala de la exposición Estancias, junto a las preguntas de la Estancia 4, en la sala de la exposición Catástrofes donde se encontraba la obra We Will All Die y en las salas de la exposición monográfica de Regina José Galindo Piel de Gallina, donde se encontraba la obra Limpieza social:

Ser espectadora para reconstruir mi identidad. El mundo de afuera está lleno de inputs y el espacio museístico me permite repensarme, centrarme en las microhistorias que no existen en otros lugares, repensarme de maneras que me hacen más libre.

Como espectadora primero pienso ¿dónde me colocan? Y luego considero ¿dónde me coloco. Para mí ser espectadora es posicionarse.

Hasta ahora el espectador ha sido muy pasivo. Cuando estoy en el taller de pintura pienso lo mismo. Todo es muy estático.

Pienso en colocar telas y otras cosas que tengan que traspasarse para llegar a las pinturas. Al espectador hay que darle más cosas que hacer.

Yo personalmente como espectadora me pienso de mucha maneras y en diferentes posiciones, espectadora-consumidora, espectadora-sumisa, espectadora-exploradora, espectadora-curiosa, espectadora-comprensiva, espectadora-reflexiva.

Pienso al espectador como la relación maestro-estudiante. El profe lo sabe todo y el estudiante está ahí para aprender cosas nuevas. Yo voy al museo y soy un contenedor vacío y en el museo me lleno.

Ser espectadora es sentirse impactada. Mirar detenidamente. Aprender nuevas ideas. Encontrarse con aperturas.

Ser espectadora es pasar tiempo mirando. Volver de nuevo al museo a mirar lo mismo para construir nuevas conexiones.

Utilizar las preguntas y las imágenes de la colección como escena de direccionalidad para hablar de quién mira y qué significa mirar, implica escuchar las respuestas de las participantes no como voces separadas cada una en su espacio individual irreducibe sino funcionando en un diálogo expansivo, viral entre ellas, la Estancia 4, las obras señaladas, las ideas y experiencias asociadas. Si hacemos esto, parece plausible leer algunos de estos testimonios en términos de asociación y extensión de la propuesta de Laboratorio (prótesis) y otros en términos de desequilibrio de dicha propuesta. El poder de la direccionalidad es escenificar estos desencajes, tensiones. Escenificar que como sujeto que aprende estoy dispuesta a ne- 
gociar mi subjetividad en el espacio/intervalo entre ser agente de significado y al mismo tiempo reconocerme conformada y quizás constreñida por los discursos sociales, culturales, estéticos que estructuran el museo, las obras, sus campos expandidos (ELLSWORTH, 2005).

Esta tensión entre agencia y construcción social implica definir la subjetividad institucional, la subjetividad-construida-en/desde/con/para-el-museo como una permanente emergencia, deseo, devenir. Conlleva que el museo y sus visitantes adopten riesgos y construyan nuevos vínculos de relación que acepten que los fallos y el desorden son necesarios para trabajar las paradojas de la direccionalidad. La direccionalidad como paradoja siempre pierde a alguien o algo. Sin dicho borrado no hay desbordamiento de marcos, discursos, narrativas; no hay posibilidad de diferencias diferenciadoras.

Existen múltiples momentos a lo largo del taller en los que se pueden reconstruir las tensiones entre agencia y construcción social. Por ejemplo, en la primera sesión las obras Muxima y The salt of the sea de Alfredo Jaar nos permitieron discutir la posibilidad de crear imágenes que permitan contemplar lo inimaginable, imágenes que no estén construidas como una forma de iconización o desrealización del evento, en la que Africa está permanentemente representada desde el tropo colonialista y generalista de un sufrimiento genérico, ahistórico, des-humanizador y que nos invitan a responder al dolor de los otros de forma afectiva y situada, transformándonos en testimonios.

Compartimos las preguntas que, según Griselda Pollock (2007), dirigieron el trabajo de Jaar cuando inició el proyecto Muxima: ¿Dónde está el factor humano? ¿Cómo un no-africano puede construir imágenes sobre África sin reproducir el legado de una cultura visual que reproduce la violencia? En este momento del seminario, el grupo pudo ver The Salt of the Sea. El departamento de conservación había dado órdenes de traerla a la sala desde los almacenes con motivo de está sesión. La obra nos acompañó por unas horas montada precariamente en un caballete.

Algunas de las respuestas de las participantes a estas preguntas se afincaron en las generalidades y entropías del relativismo: "No hay nada de cierto en las imágenes que producen y distribuyen los media", “ ¿por qué tengo que hablar específicamente de África?". Otras respuestas se localizaron en que el conocimiento sobre el factor humano se produce en el nivel de la vida cotidiana, no en los discursos difíciles del arte, de- 
fendiendo que África forma parte también de las calles, los colectivos locales, las relaciones personales. Otras respuestas afirmaron no poder relacionarse de manera relevante con The salt of the sea, sin el conocimiento y el contexto de la obra Muxima al completo. En general todas estas respuestas performan una escena de direccionalidad, que escenifica cómo la imagen del sufrimiento que ocurre en otro lugar se ha convertido culturalmente en algo ininteligible.

Como vimos anteriormente, The Salt of the Sea no es una imagen que se identifique con los esquemas de inteligibilidad tácticamente controlados por los media y los intereses políticos que los apoyan, donde, como señala Judith Butler (2004) la pérdida se desrealiza con el fin de construir socialmente una insensibilidad hacia la muerte y el sufrimiento de los otros, "convirtiéndose en el mecanismo en el que se logra la deshumanización”. Butler añade, que esta desrealización "no tiene lugar dentro o fuera de la imagen, sino a través de los marcos que la contienen" (p. 148).

Esto quiere decir, que posiblemente las respuestas y dilemas de las participantes del Laboratorio se encontraban situadas en una escena de direccionalidad paradójica, señalando las dificultades que esta imagen y su campo expandido de lenguajes trata de abordar. Es decir: cómo en el mundo que vivimos la experiencia de fragilidad, vulnerabilidad, pérdida se encuentra en los límites de nuestra capacidad de crear sentido. Performar este fallo a partir de construir una colisión entre las narrativas personales y los discursos de cultura visual dominante que evita el duelo y la humanización del conflicto constituye un momento pedagógico. Este fallo escenifica que las imágenes son conformadoras de subjetividad y que la imagen cliché es formadora de subjetividades dominantes. Como señala Deleuze (2012):

Normalmente sólo percibimos clichés porque percibimos únicamente lo que estamos interesados en percibir, por virtud de nuestros intereses económicos, nuestras creencias ideológicas y nuestras demandas psicológicas (p. 20).

Sí como hemos dicho, la imagen-tiempo evita una solución final, un espacio pedagógico de direccionalidad inspirado en la imagen tiempo permite performar cómo los participantes/ estudiantes/visitantes del museo buscan soluciones a problemas derivados de su relación con las imágenes, cómo fallan en encontrarlas o cómo las soluciones se resisten a ser definitivas.

A través de la obra Limpieza Social, y la exposición mono- 
gráfica de la obra de Regina José Galindo Piel de Gallina, abordamos una de las preguntas de la Estancia 4: ¿Cómo queremos ser representados? ¿De qué representación estamos hablando? ¿La representación como un espacio fijo, escoptofílico, de control, colonialismo y repetición de lo mismo? ¿o la antirepresentación como un espacio de memoria, testimonio, responsabilidad, reconocimiento de las pérdidas, los silencios, lo inimaginable? Para Griselda Pollock (2010), comprender la imagen como encarnamiento de la memoria implica una ética de mirar hacia atrás, no para reproducir una violencia vouyerística que cosifica al otro, ni mirar con indiferencia o dejar de mirar porque todas las imágenes en definitiva son iguales. Mirar hacia atrás (volver a mirar, revisar) implica el trabajo feminista de resistirse al borrado, mirar como testimonio, elaborar un espacio intermedio (intervalo) constituido por una tensión en la que nos abrimos afectivamente al otro al mismo tiempo que nos hacemos conscientes que el rastro visible de su experiencia es claramente tenue o inexistente, en el que la representación/visión tiene que ser reconstruida a través de relaciones sociales y discursivas, no necesariamente a través de imágenes (POLLOCK, 2010).

En este sentido, mirar hacia atrás nos enfrenta a la paradoja como señala Ellsworth (2005) de "enseñar sin una referencia positiva" (p. 155). Por una parte, no nos podemos quedar quietas en el lugar del silencio, pero por otra no es ético pretender que podemos ocupar el lugar del otro, comprender, encarnar su experiencia porque la experiencia, tanto la mía como espectadora, como la del otro están históricamente emarcadas y situadas en interrelaciones sociales y de poder y en este sentido son irrepetibles. Lo que producimos en esta relación no es una imagen, sino un acto generativo, performativo de memoria, narración, asociaciones, historias sociales, que reactualiza las relaciones.

Esto es así porque lo que se cambia es nuestra relación con los significados que circulan y compiten por su autoridad. Lo que cambia es la forma en que estamos implicados en los silencios que hacen posible el lenguaje (p. 162).

La obra de Regina José Galindo generó discusiones interesantes en nuestro Laboratorio. Refiriéndose a la obra $X X$ (2007), una de las participantes, cuestionó las razones de Galindo de no tomar ventaja de su posición privilegiada para actuar de manera más autoritaria. Esta obra consiste en la ins- 
talación de 52 lápidas en el cementario guatemalteco de La Verbena, "a cuerpos que son enterrados como XX. Cuerpos que no fueron reconocidos o reclamados" (GALINDO, 2011, p. 201). La estudiante dice lo siguiente:

Regina no es activista. Lo explicó ella misma durante la presentación de la exposición, en relación a la obra en la que se encuentra cavando tumbas de cuerpos desaparecidos. Durante la acción una mujer le dijo que conocía el nombre de uno de los cuerpos y ella continuó con la XX. Luego la mujer tuvo que ir a cambiarlo.

La participante conocía esta historia no sólo porque la artista la había compartido en su conferencia en el museo, sino también porque la instalación de la obra $X X$ no ocultaba las paradojas de su acontecimiento. Las imágenes mostraban el cavado de las tumbas, el colocado de cuerpos anónimos que son transportados en bolsas negras, la instalación de las lápidas, pero también la reacción de la mujer, la ignorancia de Regina a la llamada, el grabado precario, quizás con un palo, del nombre de un desaparecido en el mármol de una de las lápidas. La participante consideraba que la ética y la responsabilidad de la artista era ayudar a la mujer, resistirse a dejar el $X X$ en la lápida como representación única.

Sin embargo, el trabajo pedagógico de $X X$, no es adoptar un lugar de autoridad, sino construir una escena crítica de direccionalidad entre un acontecimiento, el Estado que construye fosas comunes que ignoran la individualidad e historia personal de las víctimas de la violencia y lo que en principio tal acontecimiento pretende borrar, desplazar, silenciar: las voces que se resisten al olvido y surgen como algo inesperado. El trabajo pedagógico de $X X$ es pensar la acción desde una subjetividad objetiva que es afectada por las relaciones entre partes, espacios, acontecimientos. Tomar la autoridad significaría adoptar una subjetividad volitiva, directora de acciones, que resolvería las asimetrías del poder y, así reiteraría el borrado histórico de los subalternos como víctimas pasivas sin autoridad, o capacidad resistente. La reacción inicial de la participante ante la obra $X X$ busca una resolución y un significado único, pero como señala Ellsworth (2005) a través de Phelan (1993):

[La representación] siempre lleva consigo más de lo que tiene intención de llevar y el "exceso" de significado transportado por la representación crea un suplemento. Este suplemento hace po- 
sibles las lecturas múltiples y resistentes y evita la reproducción del mismo significado o sentido formado en una lectura de un texto o acontecimiento al siguiente... La representación nunca es totalizante - nunca proporciona una imagen exacta y completa de lo que ha sido representado - siempre fracasa en reproducir lo real de forma exacta. Por consiguiente, la representación produce rupturas y brechas, haciendo que una comprensión total, completa o adecuada del mundo sea imposible (p. 163).

En la segunda sesión del Laboratorio, pedí al grupo que exploraran alguna de las salas de la exposición Piel de Gallina, donde se pudieran observar/leer/escuchar simultánemente varias obras de Galindo presentadas en diferentes formatos, ya fuesen poema, vídeo, fotografía, objeto, sonido. Les propuse que se preguntasen individualmente o en parejas por el lugar de visión que las obras construían y cuál era la localización en las que ellas decidían situarse. Sugirieron varias lecturas que apuntaban a lugares de descentramiento y movilidad entre imagen y texto, entre ver y ser vista, entre yo y otro, que señalaban cuestiones de implicación, responsabilidad, la dificultad de ser testimonio de imágenes de violencia activa, el reconocimiento de vidas y experiencias destruidas, etc... También se performaron otras lecturas realizadas desde la distancia, la no implicación, la autocomplacencia, el vouyerismo.

El espacio entre ver la performance y leer el poema es un espacio de visión más móvil que sólo mirar la obra donde tengo que preguntarme si quiero mirar esta situación tan violenta. Como mujer que mira me pregunto cómo se siente ella dentro de la cúpula.

Me preguntó si la gente no hace nada porque es un museo y a un museo se va a mirar sin necesariamente implicarse, quizás si los golpes ocurrieran en el espacio público sería diferente.

Yo no veía sangre de las víctimas, veía la sangre de la menstruación... como pone su propio cuerpo en el balde y va con una falda, pensaba en la sangre como algo que cae del cuerpo, quizás un ritual ancestral, indígena.

¿Ella utiliza el cuerpo para hablar de sí o para hablar de lo colectivo?

Ella pone un muro al hacer una acción que es arte, que tiene principio y final, no importa que occura en el espacio público, es igual que si fuera la sala de exposiciones. Yo como espectadora no voy a hacer nada, solo mirar. 
No es el objetivo de una pedagogía crítica de la direccionalidad decidir en el momento en que estas lecturas se ponen en funcionamiento cuáles son mejores, más válidas, más verdaderas. La pedagogía de la direccionalidad conecta con el pensamiento deleuziano (ACASO Y ELLSWORTH, 2011) en el sentido de ser un arte de lo múltiple, de producir conexiones que sugieren otras conexiones. Estos espacios vividos de pedagogía, en los que se escenifican diferentes lecturas, son momentos suspendidos, no definitivos (que no tienden al cierre), parciales (no deciden quién sabe y quién no sabe), que configuran una nueva lógica de posibilidad en que todo lo dicho y oído funciona en relación, produce choques y desencajes y en consecuencia posee el potencial de movilizar el discurso, los significados y las posiciones de visión en futuras lecturas.

En otras palabras, para hacer conexiones no es necesario el conocimiento, ni la certeza, ni siquiera la ontología, sino la confianza en que algo saldrá de todo ello aunque uno no esté aún totalmente seguro de qué se trata (RAJCHMAN, 2007, p. 12).

A partir de los contenidos expuestos y las exploraciones realizadas en torno a la obras de Jaar, Galindo y Eskauriaza, nos propusimos durante los dos últimos días del Laboratorio producir narrativas digitales que se relacionaran con las preguntas, los diálogos e ideas surgidas y que exploraran los códigos perceptivos y expresivos de la imagen-tiempo. Para ello nos planteamos experimentar con el video desde una aproximación Hazlo-tu-misma/Do-It-Yourself (DYI) utilizando tecnologías básicas, domésticas, cámaras incorporadas en los teléfonos móviles y el software disponible en el ordenador de cada una. El objetivo era construir una imagen como momento expandido que no pertenece a una única temporalidad, sino al reencuentro afectivo desde el presente con un registro preexistente, de otro tiempo.

Una de las participantes, Amaia se propuso trabajar con una documentación fotográfica que describe un doble movimiento de creación/borrado, y virtualidad-memoria/actualidad-historia. El vídeo es una llegada al piso de protección oficial de los abuelos de Amaia recientemente fallecidos en Mondragón, así como un recorrido por espacios y objetos afectivos, prácticamente un álbum familiar póstumo.

En este vídeo el pasado está presente a través de un circuito recolector de objetos y espacios-afectos de un otro familiar que ya no está. Pero este pasado al mismo tiempo está 
actualizado, mediante un proceso ontológico de conectar ideas en el tiempo. Vemos un tiempo de memorialización de la clase trabajadora que emigró a ciudades industriales como Mondragón, adquirió apartamentos en bloques de pisos de protección oficial y vivió modestamente y conformada. Y vemos el tiempo del presente precario e imprevisible de la imagen de un solar vallado, donde se encontraba la fábrica en la que el abuelo de Amaia había trabajado toda su vida. De la valla se alza un cartel que anuncia "Venta de viviendas de 2 y 3 habitaciones: Podemos construir tu futuro". En el muro de piedra hay pintados varios graffiti en rojo y negro; uno con la inscripción U-27 Greba Orokorra (27-E Huelga General). El movimiento a través de estos espacios provoca tensiones y densidades entre el tiempo virtual de la memoria y el tiempo real de una ciudad, un espacio público que está cambiando (la fábrica, el lugar de producción se va a convertir en un espacio residencial de clase media), pero no sin conflicto. El montaje de imágenes duplicadas intensifica el valor afectivo de estos objetos y lugares cualquiera. El contraste entre la oscuridad exterior y la luminosidad interior acentúa los desencajes entre memoria y actualidad, entre los rastros de vida vivida en el espacio doméstico, y la doble potencialidad proyectada en el espacio público, huelga general o vida residencial (ver, https://vimeo.com/60282977).

Algunas participantes en el Laboratorio, propusieron no tanto partir de una imagen como de textos que para ellas eran evocativos de imaginarios específicos. En el caso del vídeo de Mertxe, $A$ veces me siento animal, el texto es de su propia autoría. A inicios del seminario, Mertxe se plantea la posibilidad de filmar una excursión al monte que planea realizar durante la misma semana del taller.

A veces me siento animal es fundamentalmente una imagen-movimiento construida en un plano continuo, en el que la cámara es casi una prótesis-extensión del cuerpo de Mertxe, una imagen-comportamiento, corriendo, trepando, caminando, respirando por espacios naturales pedregosos, irregulares. La cámara nos ofrece unos instantes de una experiencia privilegiada. La yuxtaposición fragmentada de su voz leyendo un texto que aspira a la posibilidad de devenir animal y la finalización del plano-secuencia con el descubrimiento de la silueta de Mertxe proyectada en el terreno, nos hacen pensar en este movimento no como algo motor, sino movimiento como cambio, deseo y devenir identitario, como posibilidad de ser otro (ver, https://vimeo.com/6o282978). 
Maddelen tenía interés por situar su video en relación a alguna historia local, pero no tenía ningún texto o imagen predefinida. En la semana de desarrollo del taller, los espacios públicos de Vitoria se habían llenado de carteles, luces, adhesivos verdes en alusión a la nominación de la ciudad como Green Capital europea. Paralelamente a nuestro Laboratorio se estaban celebrando congresos y eventos en otras partes de la ciudad que traían visitantes de diferentes corporaciones del mundo a charlar de productos y procesos sostenibles. Sugerí a Maddelen buscar un buen informante a quien entrevistar sobre sus visiones del efecto Green Capital y sobre sus experiencias ordinarias de sostenibilidad; quizás algún vecino o familiar que conociera la historia reciente y popular de la ciudad y que hubiera pasado en el casco antiguo una buena parte de su vida. Ella decidió entrevistar a su abuela. Le planteé experimentar con una narrativa que yuxtapusiera dicho testimonio con planos que documentaran la virtualidad de los adhesivos y cartelitos verdes sobre los muros, edificios y suelos de piedra, constituyentes reales del ecosistema del casco antiguo.

En definitiva el vídeo de Maddelen construye una forma de ver que cambia la experiencia cotidiana de la ciudad, de la manera que nos dicen que tiene que ser vista y vivida. La tensión del testimonio con la recolección de planos del espacio público, abre el tiempo de la ciudad-corporativa y virtual a otro tiempo el de la experiencia menor y subalterna como recurso crítico, produciendo lo que Deleuze (2010) denomina la diferencia tercera, una diferencia que escenifica la brecha que divide lo menor de lo dominante (ver https://vimeo.com/60282976).

\section{Conclusiones}

El concepto pedagógico de direccionalidad y sus paradojas me ha permitido analizar tres obras de la colección ARTIUM en los términos estéticos y éticos de la imagen-tiempo que se despliega no sólo como visible sino como devenir, con la palabra, con lo que es posible decir y con lo que no es dicho en el campo visible. Una imagen que trata de producir responsividad y responsabilidad entre subjetividad y diferencia, entre construcción social y agencia individual, entre estética y ética a través de una desterritorialización de los códigos expresivos.

He tratado de señalar la existencia de posibles conexiones entre el conocimiento que estas tres obras como imágenestiempo construyen y una pedagogía de la direccionalidad 
centrada en la parcialidad, localización, experimentalidad y co-implicación en el conocimiento.

He sugerido que el museo y la exposición pueden funcionar como laboratorios de aprendizaje que renuncian al control del conocimiento y promueven la incertidumbre, evitando el cierre de las imágenes y de los significados culturales. Pero también he planteado cómo el aprendizaje desde la incertidumbre puede desafiar el andamiaje cognitivo de los intérpretes, estudiantes, visitantes provocando desequilibrio y ansiedad hacia el fallo, situándonos en escenas de direccionalidad que nos localizan en posiciones de conocimiento, poder y deseo incómodas, de las que no éramos conscientes. He defendido que este desequilibrio y fallo es esencial para la transformación subjetiva y cultural.

Más allá del concepto de la imagen-tiempo, he argumentado que la pedagogía de la direccionalidad tiene elementos en común con un pensamiento deleuziano, en el sentido en que el aprendizaje no queda determinado por la certeza de que vamos a llegar a una conclusión, sino por la idea de que todo conocimiento es parcial y posee la potencialidad de ser modificado a través de nuevas conexiones y asociaciones. Un pensamiento en el que el arte y la imagen son productoras de conocimiento en términos de experimentalidad y devenir, de lenguajes e historias menores que nos llevan a reflexionar sobre el sentido de lo colectivo desde lo afectivo y expresivo, desbordando el control comunicacional de la imagen y la violencia de los clichés impuestos por la imagen industrial.

\section{Referencias}

ACASO,M. y ELLSWORTH, E. El aprendizaje de lo inesperado. Madrid: Libros de la Catarata, 2011.

BUTLER, J. Precarious life. The Powers of mourning and violence. Londres: Verso, 2004.

COLMAN, F. . Deleuze and cinema: The film Concepts. Oxford, UK: Berg, 2011.

COWIE, E. Recording reality, desiring the real. Minneapolis: University of Minnesota Press, 2011.

DELEUZE, G. Cinema 2. The time-image. Minneapolis: University of Minnesota Press, 2010.

DIDI-HUBERMAN, G. Emotion does not say "I". The fragments on aesthetic freedom. In JAAR, Alfredo. La politique des images. Zurich: JRP|Ringier, 2007, pp. 57-70. 
ELLSWORTH,E. Posiciones en la enseñanza. Diferencia, pedagogía y el poder de la direccionalidad.Madrid: Akal, 2005.

FRENKEL, V. A place of uncertainty: Towards a new kind of museum. In POLLOCK G. e J. ZEMANS, J. Museums after modernismo. Strategies of engagement. Londres: Blackwell, 2007, pp. 119-130.

GALINDO, R. J. (2011). XX In. GALINDO, Regina José. Milán: Silvana Editoriale,2011, pp. 201-207.

GAROIAN, C. R. Performing the Museum. Studies in Art Education 42 (3), 2001, pp. 235-48.

. The prosthetic pedagogy of art. Em-bodied research and practice. Albany, NY: State University of New York Press, 2013.

HOOPER-GREENHILL, E. Museums and The Interpretation of Visual Culture. Londres y Nueva York: Routledge, 2000. . Museums and Education: Purpose, Pedagogy, Performance. Londres y Nueva York: Routledge, 2007.

PHELAN, P. Unmarked: The politics of performance. Nueva York: Routledge, 1993.

POLLOCK, G. Not-forgetting Africa: The dialectics of attention/inattention, seeing/denying, and knowing/understanding in the positioning of the viewer by the work of Alfredo Jaar. In. JAAR, Alfredo. La politique des images. Zurich: JRP|Ringier, 2007, pp. 113-136.

. Encuentros en el museo feminista virtual. Tiempo, espacio y el archivo.Madrid: Cátedra, 2010.

POLLOCK, G. \& ZEMANS, J. Museums af-ter Modernism: Strategies of Engagement. Malden, MA y Oxford, UK: Blackwell, 2007.

RAJCHMAN, J. Deleuze: Un mapa. Buenos Aires: Nueva Visión, 2007.

RUSHTON, R. Cinema after Deleuze. Londres y Nueva York: Continuum, 2012.

VILLAESPESA, M. \& BNV Producciones. Estancias: Prácticas Restituyentes de la colección ARTIUM[Folleto de exposición]. Vitoria-Gasteiz: ARTIUM/Departamento de Cultura del Gobierno Vasco, 2011.

Recebido em: 30/o9/13

Aceito em: 30/10/13 


\section{LAURA TRAFÍ-PRATS}

\section{trafilaura@hotmail.com}

Professora Associada de Educação Artística e Estudos Visuais na Universidade de Wisconsin-Milwaukee. Laura Trafí-Prats foi professora na Universidade de Barcelona e na Universidade Autônoma de Barcelona. Já publicou inúmeros artigos em revistas como Studies in Art Education, The International Journal of Art and Design Education, Visualidades, Instrumentos y Cuadernos de Pedagogía. Sua investigação atual centra-se na produção de conhecimento artístico e educativo com base na resistência à clausura de sentido, na crise do conhecimento e nas linguagens minoritárias e anti-representacionais. 